\title{
THE
}

\section{A Comparison between Observations and MM5 Simulations of the Marine Atmospheric Boundary Layer across a Temperature Front}

Qingtao Song

University of Rhode Island

Tetsu Hara

University of Rhode Island, thara@uri.edu

Peter C. Cornillon

University of Rhode Island, pcornillon@uri.edu

Carl A. Friehe

Follow this and additional works at: https://digitalcommons.uri.edu/gsofacpubs

\section{Citation/Publisher Attribution}

Song, Q., T. Hara, P. Cornillon, and C.A. Friehe, 2004: A Comparison between Observations and MM5 Simulations of the Marine Atmospheric Boundary Layer across a Temperature Front. J. Atmos. Oceanic Technol., 21, 170-178. doi: 10.1175/1520-0426(2004)0212.0.CO;2

Available at: https://doi.org/10.1175/1520-0426(2004)021\%3C0170:ACBOAM\%3E2.0.CO;2

This Article is brought to you for free and open access by the Graduate School of Oceanography at DigitalCommons@URI. It has been accepted for inclusion in Graduate School of Oceanography Faculty Publications by an authorized administrator of DigitalCommons@URI. For more information, please contact digitalcommons-group@uri.edu. 


\title{
A Comparison between Observations and MM5 Simulations of the Marine Atmospheric Boundary Layer across a Temperature Front
}

\author{
Qingtao Song, Tetsu Hara, And Peter Cornillon \\ Graduate School of Oceanography, University of Rhode Island, Narragansett, Rhode Island \\ CARL A. FrieHE \\ Department of Mechanical Engineering, University of California, Irvine, Irvine, California
}

(Manuscript received 20 March 2003, in final form 10 July 2003)

\begin{abstract}
Simulations, made with the fifth-generation Pennsylvania State University (PSU)-National Center for Atmospheric Research (NCAR) Mesoscale Model (MM5), of the response of the marine atmospheric boundary layer (MABL) as air moves over a sharp SST front are compared with observations made during the Frontal Air-Sea Interaction Experiment (FASINEX) in the North Atlantic subtropical convergence zone. The purpose of undertaking these comparisons was to evaluate the performance of MM5 in the vicinity of an SST front and to determine which of the planetary boundary layer (PBL) parameterizations available best represents MABL processes. FASINEX provides an ideal dataset for this work in that it contains detailed measurements for scenarios at the two extremes: wind blowing from warm to cold water normal to a $2^{\circ} \mathrm{C} \mathrm{SST}$ front and the converse, wind blowing from cold to warm water.

For the wind blowing from warm to cold water, there is a pronounced modification of the near-surface wind field over the front, in both model results and aircraft observations. The decrease of near-surface wind speed and stress is due to a stable internal boundary layer (IBL) induced by the SST front, restricting exchange of mass and momentum between the surface and upper part of the MABL. For the cold-to-warm case, the relatively strong vertical mixing through the entire MABL over warm water dampens the response of the near-surface winds and surface stress to the SST front. The properties observed by the aircraft are simulated quite well in both cases, suggesting that MM5 captures the appropriate boundary layer physics at the mesoscale or regional scale.
\end{abstract}

\section{Introduction}

A number of recent studies have shown significant modification of scatterometer-derived surface wind stress in the vicinity of sea surface temperature (SST) fronts with SST change of as little as a few degrees (Cornillon and Park 2001; Park and Cornillon 2002; Wentz et al. 2000; Chelton et al. 2001). Two mechanisms have been hypothesized to explain these observations: modification due to changes in the stability of the marine atmospheric boundary layer (MABL) as the wind crosses the front (Park and Cornillon 2002; Wentz et al. 2000) and changes in the wind stress due to the motion of the ocean surface relative to the wind (Cornillon and Park 2001; Kelly et al. 2001). Recent observations in the vicinity of the Gulf Stream (a strong current associated with a sharp SST front) suggest, however, that either other processes or nonlinear interactions between the hypothesized processes play a role in mod-

Corresponding author address: Qingtao Song, Graduate School of Oceanography, University of Rhode Island, Narragansett, RI 02882. E-mail: qsong@gso.uri.edu ifying the surface wind stress as determined from satellite-borne scatterometers. In order to better understand these processes, we decided to use the fifth-generation Pennsylvania State University (PSU)-National Center for Atmospheric Research (NCAR) Mesoscale Model (MM5), a fully three-dimensional (3D) meteorological model with several different (user selectable) planetary boundary layer (PBL) parameterizations. Prior to undertaking this analysis, however, it was necessary to select the boundary layer parameterization available to MM5 that best resolves changes in the surface wind stress at the meso- $\gamma$ scale $(2-20 \mathrm{~km})$ in the vicinity of an SST front and to evaluate the performance of the model using the selected parameterization. This selection and evaluation was done through comparison of MM5 simulations with in situ observations made during the Frontal Air-Sea Interaction Experiment (FASINEX) (Friehe et al. 1991).

Admittedly, the response of the MM5 boundary layer has been extensively tested over land (Pleim and Xiu 1995; Davis et al. 1999; Bright and Mullen 2002), but there have been no studies to date in which in situ ob- 
servations have been used to evaluate the performance of the MM5 PBL near oceanic fronts. In the following we report on MM5/FASINEX comparisons.

Air-sea interaction on horizontal scales of 1-100 km was studied in a region of sharp horizontal SST gradients during FASINEX in February 1986. Modification of the lower MABL by a $2^{\circ} \mathrm{C} \mathrm{SST} \mathrm{step} \mathrm{over} 10 \mathrm{~km}$ was observed by aircraft and ships in the Sargasso Sea (Friehe et al. 1991). Changes in synoptic-scale weather on three successive days (16-18 February 1986) provided near-surface winds parallel and perpendicular to the SST front. For the wind perpendicular to the front, wind from both cold-to-warm and warm-to-cold surface temperatures occurred. In situ flux and turbulence observations were made during each day. Ship soundings were made on each side of the front for the warm-to-cold case. Wind speed, direction, wind stress, wind stress direction, and sensible heat flux were observed in detail across the front on the same day from the NCAR Electra aircraft flying in a radiator pattern at 30-m height.

The next section describes the modifications that we made to the MM5 preprossessing steps that are used to initialize the model as well as the model setup. In section 3 the model performance is discussed through comparisons with available observations made during FASINEX. The results of this analysis are summarized in section 4 .

\section{The numerical model}

\section{a. Idealized initialization}

MM5 is a 3D, multinested, nonhydrostatic or hydrostatic, terrain-following $\sigma$-coordinate model designed to simulate or predict mesoscale and regional-scale atmospheric circulation. This model has been widely used for mesoscale studies (Dudhia 1993; Grell et al. 1995). MM5 is designed for real-data modeling studies, and most of the previous research with MM5 has been initialized with observational/objective-analysis data. To perform the studies of interest here, the response of the marine boundary layer to discontinuities in properties of the ocean surface, the MM5 built-in preprocessors lack the ability to generate the idealized initial and boundary conditions. A uniform flow field was required for the analysis undertaken here. To study the response of a horizontally uniform flow to the oceanic forcing eliminates the complexity of interpreting the basic processes involved. This field was generated assuming geostrophic and hydrostatic balances. The following suite of equations was solved to generate the initial conditions:

- The isobaric coordinate form of the geostrophic relationship:

$$
\mathbf{U}_{g}=\frac{g_{o} \mathbf{k}}{f} \times \nabla_{p} Z,
$$

where $\mathbf{U}_{g}$ is the geostrophic wind, $f$ is the Coriolis parameter, $Z$ is geopotential height, $g_{0} \equiv 9.80665 \mathrm{~m}$ $\mathrm{s}^{-2}$ is the global average of gravity at mean sea level, and $\boldsymbol{\nabla}_{p}$ is the horizontal gradient operator applied with pressure held constant.

- The hypsometric equation:

$$
Z_{T_{v}} \equiv Z_{2}-Z_{1}=\frac{R_{d}}{g_{o}} \int_{p_{2}}^{p_{1}} T_{v} d \ln p,
$$

where $Z_{T_{v}}$ is the thickness of the atmospheric layer between the pressure surfaces $p_{2}$ and $p_{1}, R_{d}$ is the gas constant for dry air, and virtual temperature $T_{v}$ is given by

$$
T_{v}=T\left(1+0.608 q_{v}\right),
$$

where $q_{v}$ represents the water vapor mixing ratio in kilograms per kilogram.

- The equation of state for moist unsaturated air:

$$
p=\rho R_{d} T_{v},
$$

where $\rho$ is density of moist air.

The initial conditions were generated using these equations in the following four-step procedure.

1) Specify the temperature, humidity, and wind profiles at each pressure level (more on this in section $2 \mathrm{~b}$ ).

2) Use Eq. (1) to calculate the geopotential height field at the lowest pressure level.

3) Calculate the thickness between adjacent pressure levels using the hypsometric equation (2). The results of this calculation, together with the geopotential height field at the lowest pressure level obtained in step 2, are then used to generate the geopotential height field at each pressure level.

4) Calculate the surface pressure field using the hydrostatic equation $d p=-\rho g d z$ and the geopotential height field at the lowest pressure level, where density $\rho$ is determined by Eq. (4).

The preprocessor modules of the MM5 modeling system used are TERRAIN, REGRID, and INTERPF. The characteristics of the surface in the model domain are specified in TERRAIN. The surface pressure, relative humidity, geopotential height, wind vector, and temperature fields at each pressure level generated by the above four-step procedure, as well as SST, are stored as intermediate data files. REGRID horizontally interpolates the idealized pressure level data to the model grids by using the domain information set in TERRAIN. The INTERPF module then vertically interpolates pressurelevel data from REGRID to the model's $\sigma$ coordinates, generating the initial and boundary conditions required to run the model. This method of initialization only works in an unsheared environment with no thermal wind effect.

\section{b. Model configuration}

For the analysis presented herein, MM5 has been configured with two nested domains. The inner domain, 


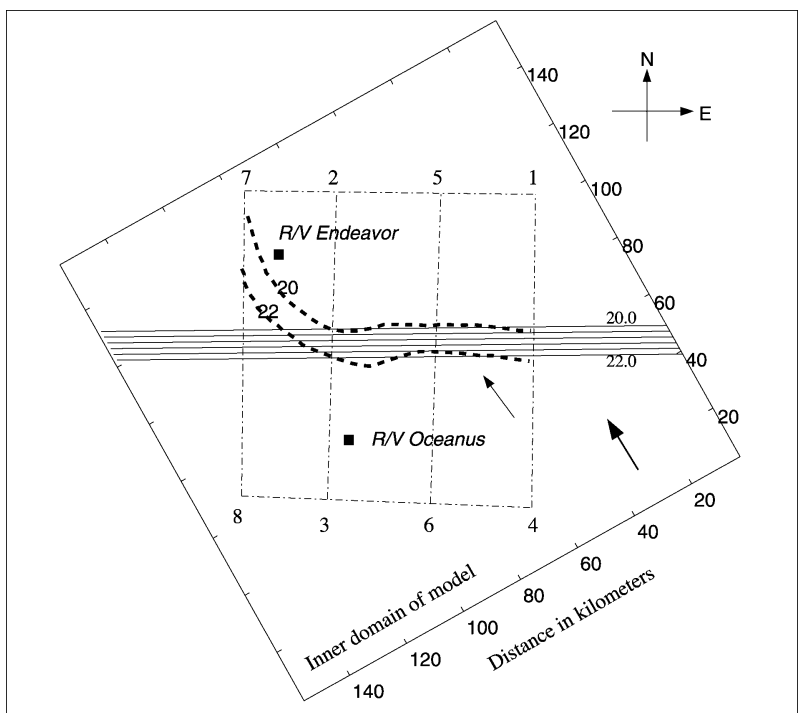

FIG. 1. The model configuration. The thick dashed lines represent the SST pattern observed during FASINEX (18 Feb 1986) overlaid by the radiator-pattern flight tracks, which are shown as thin dashdot lines. The contours are for model SST values. Thick and thin arrows indicate geostrophic wind direction and near-surface wind direction, respectively. The domain is rotated such that the nearsurface wind intersects the front at approximately $150^{\circ}$, which is consistent with the observation. Solid squares are the ship positions at 1500 UTC.

centered on the FASINEX region, is a $52 \times 52$ element grid with a grid spacing of $3 \mathrm{~km}$. The corresponding oceanic field is defined on the same grid. The resolution of the grid was chosen to allow full representation of the SST front observed during FASINEX. The outer domain, which is used to provide improved lateral boundary conditions to the inner domain, is configured as 40 meridional grid points by 50 zonal grid points with a grid spacing of $9 \mathrm{~km}$. The model was run with two vertical resolutions: $23 \sigma$ levels with 10 concentrated in the 2-km lower layer and $40 \sigma$ levels with 25 concentrated in the 2-km lower layer. The results show insignificant changes between the two vertical resolutions. Therefore, only model simulations with 23 vertical levels are presented in the manuscript.

In the present study, we simulated the case of air flowing from cold to warm water (16 February 1986) and the case of air flowing from warm to cold water (18 February 1986). An SST front of approximately $2^{\circ} \mathrm{C}$ in $10 \mathrm{~km}$ existed in the FASINEX area for the two cases during the aircraft overflights. On 18 February 1986, the winds observed from the aircraft blew from the warm side of the front to the cold side, intersecting the front at approximately $150^{\circ}$ (angle measured clockwise from north to the direction from which the wind was blowing, i.e., using the meteorological convention. A wind direction of $180^{\circ}$ implies flow toward the north). The MM5 model domains were rotated such that the direction in which the geostrophic wind (wind above the MABL) blew was from model domain west to model

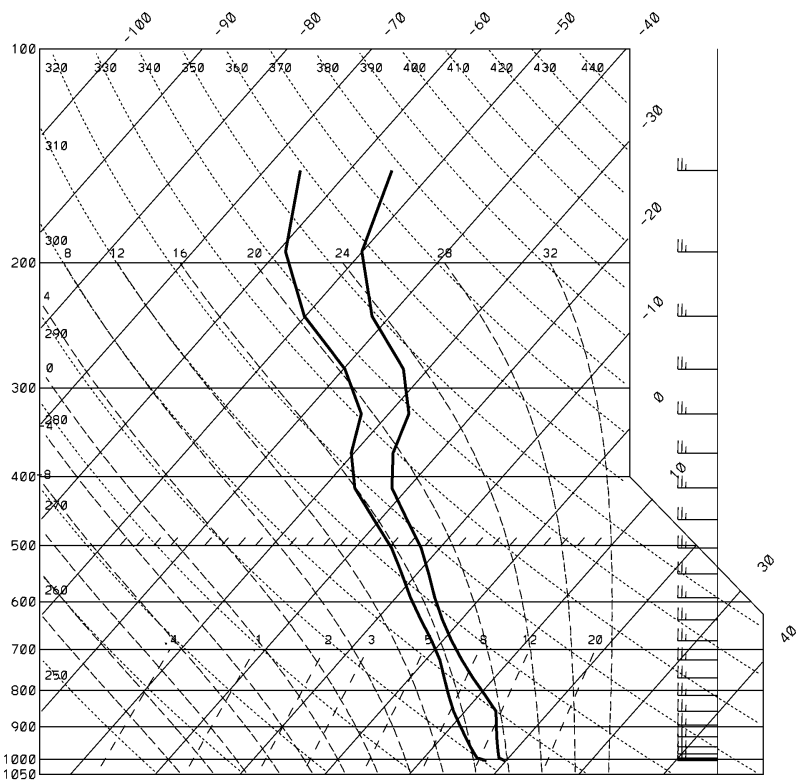

FIG. 2. Initial marine sounding of R/V Oceanus at 0000 UTC 18 Feb 1986. The left curve is the dewpoint, while the right one is the temperature profile. The wind vector is set vertically uniform to approximate the marine sounding.

domain east. Forcing with a zonal wind in MM5 eliminates problems that arise from the boundaries if the wind blows from the boundaries at an angle. Our preliminary tests have confirmed that the results obtained using a zonal wind versus a meridional wind in the model were identical. The orientation of the model domain has no dynamical effect on the results of the meso$\gamma$-scale numerical tests. The SST front was represented in the model as shown in Fig. 1. Its orientation was chosen to match that observed during the aircraft overflights for the portion of the front to which the wind vector was approximately normal.

For the warm-to-cold case, the vertical profile used to initialize the temperature and moisture fields in the model (step 1 in the four-step process described in section 2a) was based on an upstream sounding obtained from R/V Oceanus at 0000 UTC 18 February 1986, within $15 \mathrm{~h}$ of the NCAR Electra aircraft observations (Fig. 1). The atmospheric flow field above the MABL is set to be horizontally uniform with a wind speed of $13.0 \mathrm{~m} \mathrm{~s}^{-1}$, which approximates the speed obtained from the R/V Oceanus sounding. Figure 2 shows the temperature and humidity profiles obtained by $\mathrm{R} / \mathrm{V}$ Oceanus. Note that the atmosphere is relatively warm and stable.

Physical options for all the model simulations include Dudhia's simple ice scheme (Dudhia 1993) and Grell's cumulus parameterization (Grell et al. 1995). The cloudradiation scheme has been selected to account for longwave and shortwave interactions with explicit cloud and clear air, allowing diurnal variation during the simula- 

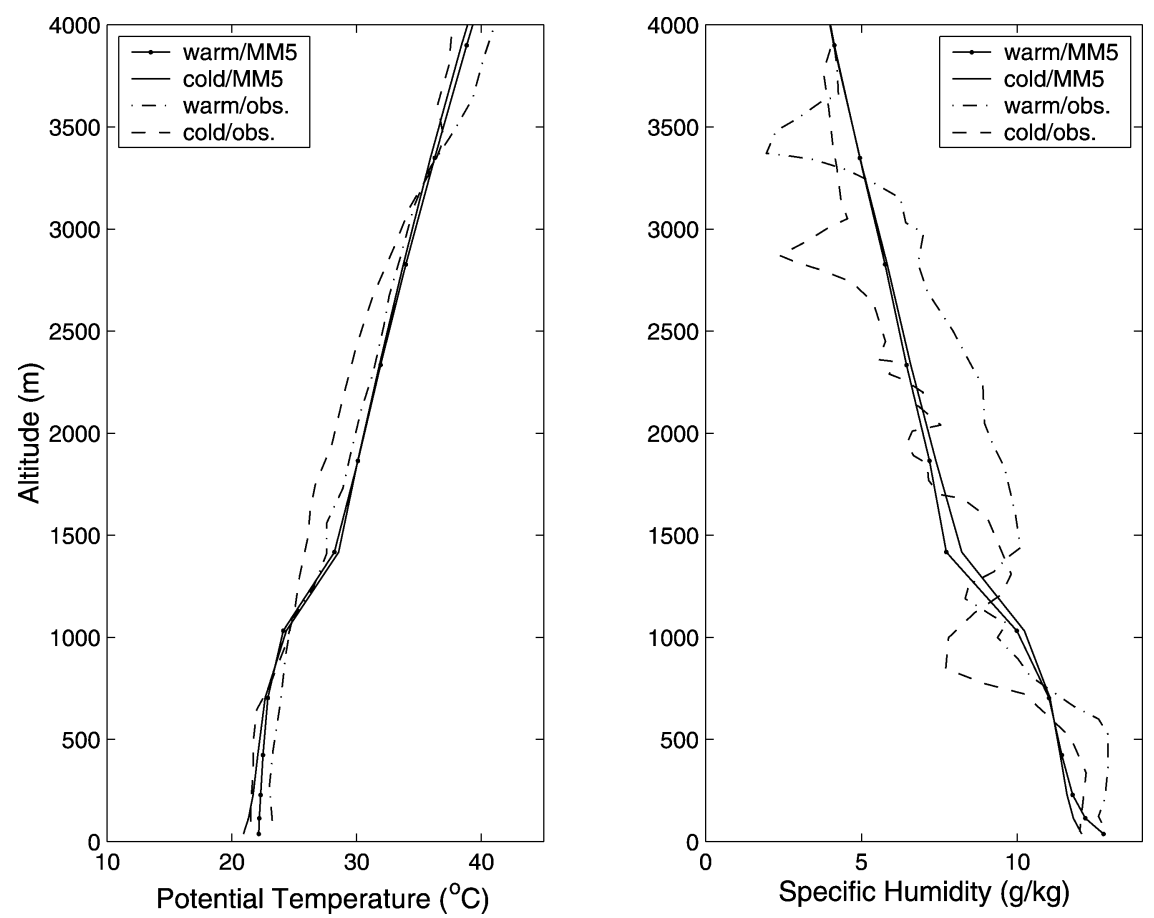

FIG. 3. Simulations (initialized with ship soundings) vs observations on 18 Feb 1986: (left) potential temperature and (right) specific humidity profiles.

tion. Nonhydrostatic dynamics with a 3D Coriolis force were used because of the high spatial resolution.

MM5 contains seven different PBL schemes to represent the boundary layer processes. The bulk PBL scheme (Deardorff 1972) is excluded from the simulations because it is only suitable for coarse vertical resolution in the boundary layer (Grell et al. 1995). The Pleim-Chang scheme (Xiu and Pleim 2001), designed to simulate the essential land surface and vegetation processes and exchange with the PBL, is also not selected in this study. In simulating the MABL processes with high vertical resolution, five PBL schemes are available in MM5: the Blackadar high-resolution scheme (Zhang and Anthes 1982), the National Centers for Environmental Prediction (NCEP) Medium-Range Forecast Model (MRF) scheme (Hong and Pan 1996), the Burk-Thompson scheme (Burk and Thompson 1989), the Eta scheme (Janjic 1994), and the GaynoSeaman scheme (Shafran et al. 2000). These PBL schemes are logically grouped into two general categories: local schemes (Burk-Thompson, Eta, and Gayno-Seaman) and nonlocal schemes (Blackadar and MRF). The model was run, initialized as described above, using each of the five PBL schemes, and the output was compared with FASINEX observations. The results shown in subsequent sections, obtained using the MRF scheme, are those that best approximated the FASINEX data. MRF is a high-resolution PBL model that incorporates the nonlocal boundary layer vertical diffusion scheme. It includes vertical diffusion in the stable atmosphere and moist vertical diffusion in clouds. Sur- face fluxes are calculated as in the Blackadar high-resolution parameterization (Zhang and Anthes 1982).

\section{Results}

The simulation involved a $15-\mathrm{h}$ integration for the outer domain. Six hours into the run, the fine-resolution inner domain began to run interactively with the outer domain. During the simulation, the SST field was kept constant. The MABL reached nearly steady state approximately $6 \mathrm{~h}$ into the fine-resolution simulation (approximately $12 \mathrm{~h}$ into the run). The model results presented in this paper are those at the end of 15-h integration. During the spinup period frictional turning of the wind occurs in the lower layers and there exists a small directional vertical shear in the steady-state wind, as seen in Fig. 1 (cf. thick and thin arrows).

The aircraft (NCAR Electra) data used in the comparisons presented here are data obtained at 30-m height from the Atmospheric Technology Division (ATD) of NCAR. In order to examine the small-scale variability of the flux fields across the front, we calculated the instantaneous flux (covariance of turbulent fluctuations) fields from the 20-sample-per-second aircraft data. The method used to calculate the instantaneous fluxes is based on Friehe et al. (1991) and Nicholls (1978). We compared our flux calculations with those presented by Friehe et al. (1991) and the results were found to be identical. 

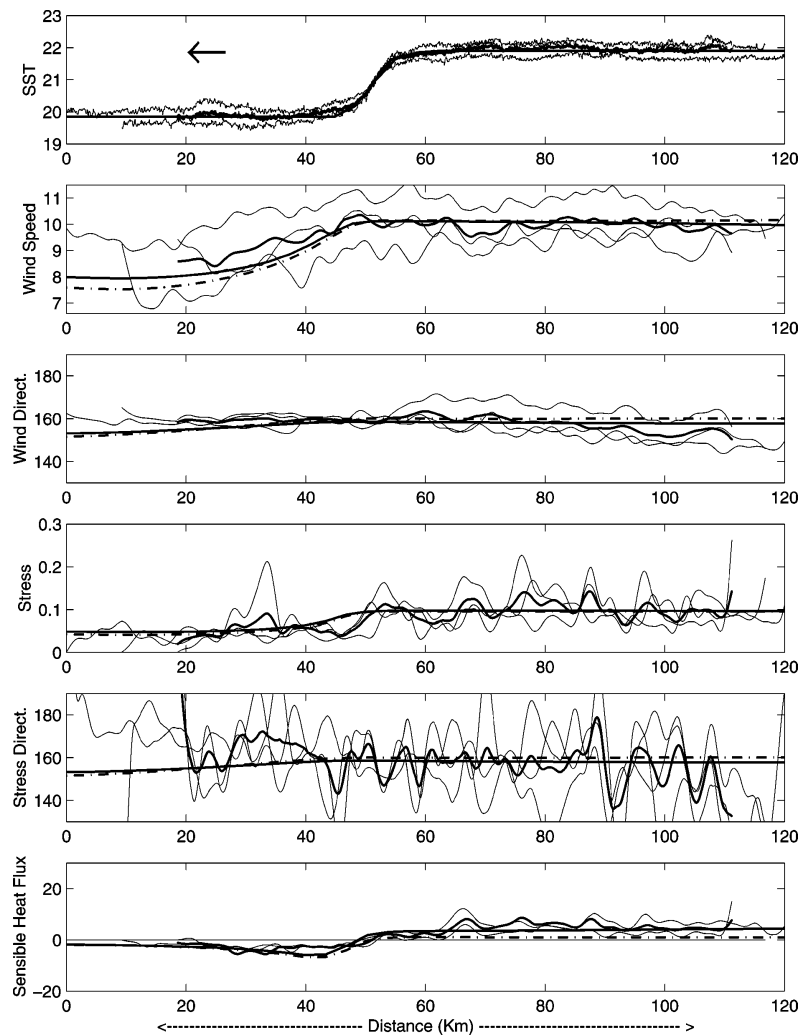

FIG. 4. Model results vs observations for the warm-to-cold case Thick smooth solid lines represent the model results initialized with ship soundings after 15-h integration; thick smooth dash-dot lines are model results initialized with NCEP reanalysis; thin lines are observations along each flight track; thick lines are observations averaged along three fight tracks. SST $\left({ }^{\circ} \mathrm{C}\right)$, wind speed $\left(\mathrm{m} \mathrm{s}^{-1}\right)$, wind direction (deg), wind stress $\left(\mathrm{m}^{2} \mathrm{~s}^{-2}\right)$, wind stress direction ( $\mathrm{deg}$ ), and sensible heat flux $\left(\mathrm{W} \mathrm{m}^{-2}\right)$ are plotted.

\section{a. The warm-to-cold case}

For the MABL wind blowing from warm to cold water, the SST front observed during FASINEX is not perfectly straight, as shown in Fig. 1. This may give rise to $3 \mathrm{D}$ effects that we have not tried to simulate in this study. In fact, some of the contour plots of wind stress presented by Friehe et al. (1991) show rather strong alongfront variability. For this reason we only used fluxes obtained from the three tracks (tracks 14, 56, and 23, as shown in Fig. 1) with the largest wind/ front angles; that is, we excluded the data from track 78 , for which the wind was nearly parallel with the front.

The potential temperature and specific humidity profiles from the numerical model and from ship soundings are shown in Fig. 3 for both sides of the front. The profiles from the model output are selected near the ship location for each side. The similarity in the shape of these curves on both sides of the front suggests good agreement in the vertical structure between model results and observations, with the MABL on the warm side being only slightly warmer and moister near the bottom.
Figure 4 presents the warm-to-cold model results (thick smooth solid lines in each panel) at 30-m height together with the observations for the wind speed, wind direction, wind stress, wind stress direction, and sensible heat flux as a function of horizontal distance across the front. The results of the model simulation capture the basic sense of the changes in MABL properties from one side of the front to the other that are evident in the FASINEX observations. The wind speeds from both MM5 and FASINEX show a steady gradual decrease downstream of the front. The model surface wind speed, based on the lowest MM5 computational level, decreases from about $10.0 \mathrm{~m} \mathrm{~s}^{-1}$ over the upstream warm water to around $8.0 \mathrm{~m} \mathrm{~s}^{-1}$ over the downstream cold water. The sensible heat flux curves show that the decrease in SST is enough to actually change the sign of the buoyant stability from unstable to slightly stable (Friehe et al. 1991). The magnitude of the model surface kinematic wind stress drops by approximately a factor of 2 at the front, from $0.1 \mathrm{~m}^{2} \mathrm{~s}^{-2}$ over the warm side to about 0.05 $\mathrm{m}^{2} \mathrm{~s}^{-2}$ over the cold side. Neither the model results nor the observations show significant variation of wind direction across the front: The model wind rotates by approximately $5^{\circ}$ as it crosses the front, whereas there is no apparent rotation in the observed wind direction averaged over the three flight tracks.

In order to better understand how the atmosphere as a whole adjusts to the surface forcing we plot, in Fig. 5 , a cross section of potential temperature $\theta$ normal to the front from the surface to $750 \mathrm{mb}$. Since the simulated front is straight, there is no alongfront variation in the potential temperature at any given height. The contours in a similar plot of $\theta$ for the initial conditions would show horizontal lines, and the contour values along the upstream boundary $(0 \mathrm{~km}$ in the figure) would be very similar to those along the upstream boundary in Fig. 5. The largest horizontal gradient in $\theta$ is found across the front at the surface. The sharp increase of $\theta$ between 900 and $850 \mathrm{mb}$ indicates the top of a mixed layer that is slightly lower on the downstream cold side of the front. Above the mixed layer, the horizontal variability of $\theta$ is typically small, although the atmosphere is still adjusting to the front. In the mixed layer, the contrast of the well-mixed section over the upstream warm water to a more stratified section downstream indicates that a stable internal boundary layer (IBL) has formed within the MABL over the cold water. This stable IBL restricts the downward momentum flux from the higher-speed winds aloft. Thus a lower-speed-wind region is formed in the IBL due to the stability brought by the advection of air blowing from warm to cold water.

The agreement with observations of the near-surface adjustment in the MM5 MABL to the SST step for the warm-to-cold case is also evident in the plot of sensible heat flux (Fig. 4). The front is characterized by a $2^{\circ} \mathrm{C}$ decrease in SST over $10 \mathrm{~km}$. The sensible heat flux shows rapid adjustment to the SST front, changing its 


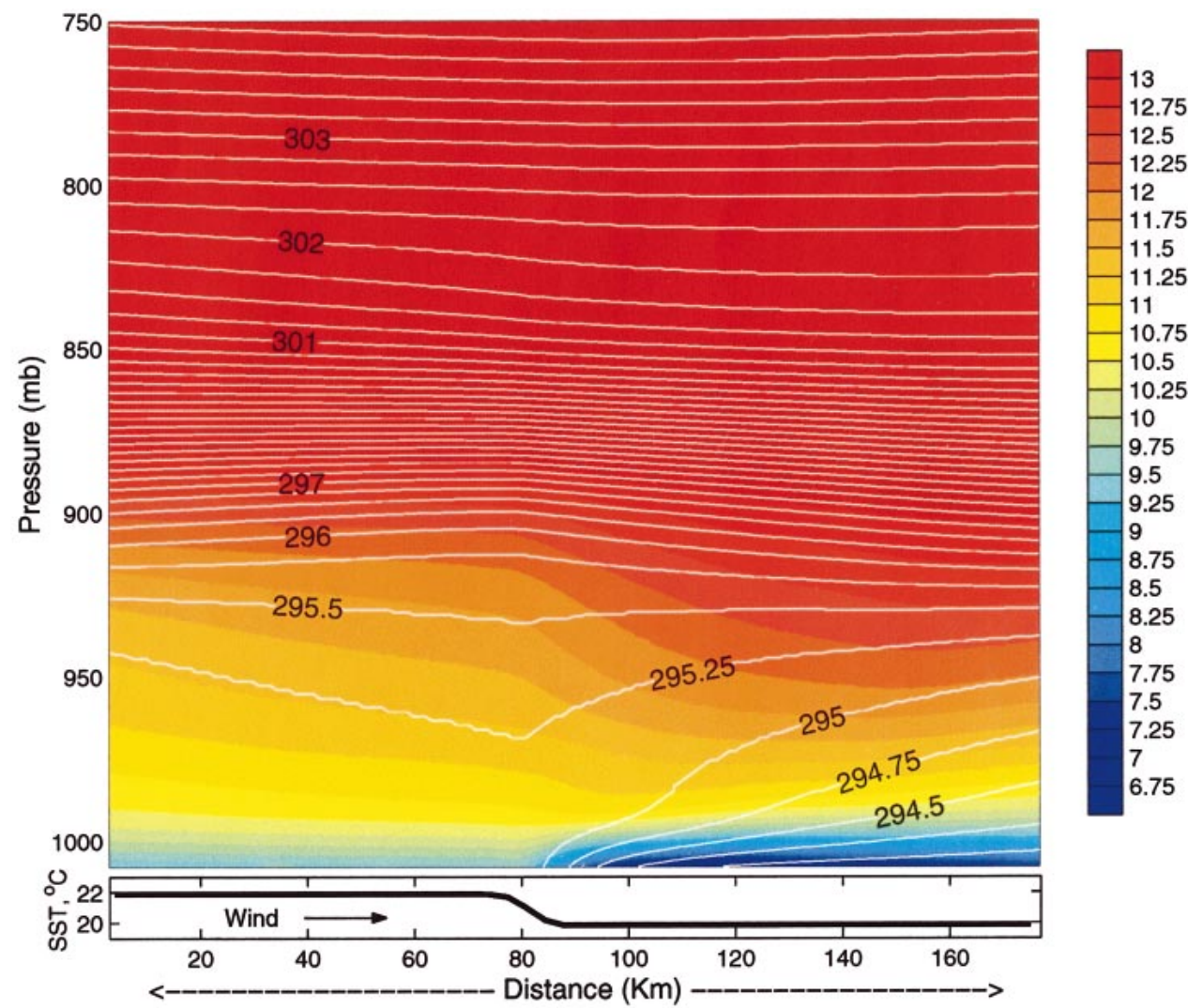

FIG. 5. (top) Potential temperature and wind speed as a function of cross-frontal distance and pressure for the warm-to-cold case at the end of the 15-h simulation (initialized with ship soundings). Contour lines are potential temperature on a contour interval of $0.25 \mathrm{~K}$. Colors represent wind speed with color steps in 0.25 $\mathrm{m} \mathrm{s}^{-1}$. (bottom) SST and wind direction at the surface.

sign from positive to slightly negative downstream of the front.

\section{b. The cold-to-warm case}

On 16 February 1986, the wind blew from cold to warm water very nearly perpendicular to the east-westoriented SST front (Friehe et al. 1991). Due to the lack of ship sounding data, we used the temperature and humidity profiles observed by the National Oceanic and Atmospheric Administration (NOAA) WP3D aircraft upstream of the front that showed an MABL near-neutral stratification capped by an inversion layer. Model boundary conditions, which were held constant for the entire run, were adjusted such that the upstream nearsurface wind at the end of the 15-h simulation, the time at which the comparison between the model simulations and the aircraft observations was made, was similar in magnitude and direction (relative to the front) to the aircraft observations.

The model results versus observations for this case are shown in Fig. 6 at the same height, $30 \mathrm{~m}$, used in Fig. 4. The range of the axes of each panel in Fig. 6 is identical to that of the corresponding panel in Fig. 4 to facilitate comparison of the two. The alongfront variation for each of the parameters (the range of thin lines in the figure at any cross-front location) is substantially larger than that for the warm-to-cold case. The crossfront variability is also larger, especially for the wind stress and sensible heat flux, indicating relatively stronger convective mixing on both sides of the front. The MM5 near-surface wind shows a systematic increase in speed from $8.1 \mathrm{~m} \mathrm{~s}^{-1}$ over the upstream cold water to approximately $8.5 \mathrm{~m} \mathrm{~s}^{-1}$ over the warm water. There is no discernable change in the observed wind speed or direction averaged over the four tracks. The sensible heat flux, positive on both sides of front, changes appreciably across the front, with the maximum rate of change near the front. Both MM5 and observations show a very rapid adjustment of the sensible heat flux to the front, over a distance of about $10 \mathrm{~km}$.

The increase of the MM5 near-surface wind speed for this case is substantially smaller $(\approx 5 \%)$ than the decrease in wind speed for the warm-to-cold case $(\approx 20 \%)$ presented in section $3 \mathrm{a}$. We believe that the major reason is the different mixing processes at work in the mixed layers in the two cases. This is best seen by a comparison of Fig. 7 with Fig. 5. Figure 7 is a 

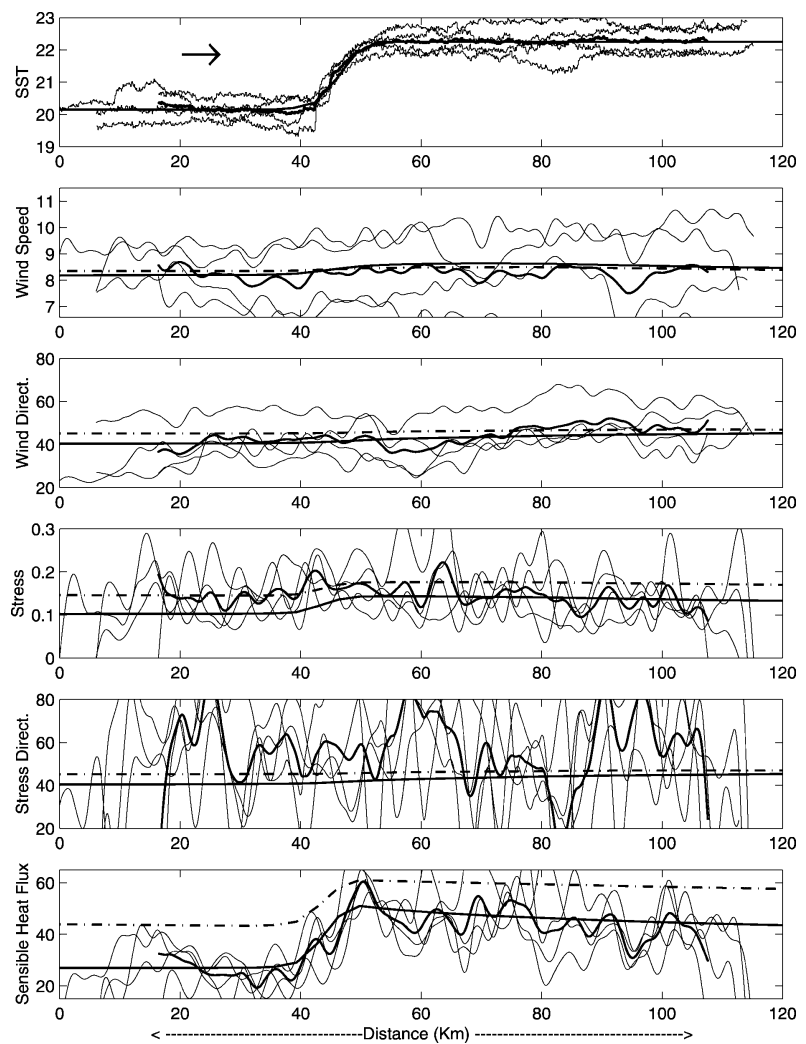

FIG. 6. Model results vs observations for the cold-to-warm case. Thick smooth solid lines represent the model results initialized with aircraft data after 15-h integration; thick smooth dash-dot lines are model results initialized with NCEP reanalysis; thin lines are observations along each flight track; thick lines are observations averaged along four fight tracks. SST $\left({ }^{\circ} \mathrm{C}\right)$, wind speed $\left(\mathrm{m} \mathrm{s}^{-1}\right)$, wind direction (deg), wind stress $\left(\mathrm{m}^{2} \mathrm{~s}^{-2}\right)$, wind stress direction (deg), and sensible heat flux $\left(\mathrm{W} \mathrm{m}^{-2}\right)$ are plotted.

cross-sectional plot of $\theta$ and wind speed plotted in the same fashion as in Fig. 5. The potential temperature and wind fields in Fig. 7 are very different from those in Fig. 5. The near-surface potential temperature over the upstream cold water $(\approx 292 \mathrm{~K})$ is slightly lower than the underlying SST $(\approx 293 \mathrm{~K})$, a difference that is accentuated over the downstream warm water, 292.5 over $295 \mathrm{~K}$. The air-sea temperature difference results in relatively strong mixing on both sides of the front. This is also evident in the sensible heat flux (Fig. 6). At each location within the mixed layer on both sides of the front, the small vertical variation of potential temperature reflects a well-mixed MABL. This well-mixed layer, especially over the downstream warm water, implies that nonlocal boundary layer vertical diffusion resulting from large eddies transports mass and momentum to/ from the surface more efficiently than does local diffusion. So, although there is an increase in the nearsurface wind speed across the front, it is much smaller than the decrease in near-surface wind speed for the warm-to-cold case in which the IBL tends to isolate the near-surface winds from the winds aloft.

\section{c. Model results initialized with NCEP reanalysis}

In addition to using the FASINEX observations (ship soundings and stack-pattern aircraft data), we have also used NCEP reanalysis data to initialize the model for both cases. The NCEP reanalysis is available at $6-\mathrm{h}$ intervals with a horizontal grid spacing of about 275 $\mathrm{km}$. The temperature and humidity profiles obtained from the NCEP reanalysis in the FASINEX area are used to set up the model. The model results for the warm-to-cold case initialized with NCEP reanalysis data are plotted as dash-dot lines in each panel of Fig. 4. The results of the simulation-near-surface wind speed, wind direction, wind stress, wind stress direction, and sensible heat flux-initialized with NCEP reanalysis data are in good agreement with those initialized with ship soundings.

The model results for the cold-to-warm case obtained by initializing with the NCEP reanalysis data are plotted in Fig. 6 (dash-dot lines) with the results obtained from the model initialized with NOAA WP3D aircraft data (heavy smooth solid lines). The two simulations show general agreement in near-surface wind speed, wind direction, and wind stress direction, whereas the values of stress and sensible heat flux simulated with the NCEP reanalysis initialization are substantially larger than those resulting from the run initialized with stack-pattern aircraft data. Although both the NOAA WP3D aircraft data and those of the NCEP reanalysis show similar thermodynamic vertical structures, that is, near-neutral stratification capped by an inversion layer, the near-surface temperature $(1000 \mathrm{mb})$ obtained from the aircraft is about $17.8^{\circ} \mathrm{C}$ compared with $15.2^{\circ} \mathrm{C}$ obtained in the NCEP reanalysis. Since the turbulent fluxes rely to a large extent on air-sea temperature differences with other conditions being held constant, the simulation initialized with data from the NCEP reanalysis shows larger momentum and sensible heat fluxes. All of the variables studied, however, show similar cross-frontal variation; that is, the slopes of the curves are similar between simulations.

To determine whether it was in fact the air-sea temperature difference that gave rise to the differences cited in the previous paragraph, the model was initialized with the NCEP reanalysis data but with $2.6^{\circ} \mathrm{C}$ added to the entire profile. The results of this run (not shown here) were indeed similar in magnitude, for all of the variables considered, to those obtained from the model when forced with the aircraft data, although the step obtained in sensible heat flux across the front was slightly smaller than that obtained when initialized with the aircraft data.

These results suggest that for studies of the MABL response to horizontal variability in the SST field using $M M 5$, the vertical structure of the atmosphere obtained from the NCEP reanalysis is an acceptable proxy for the actual vertical structure in the FASINEX region for the initialization of the model. 


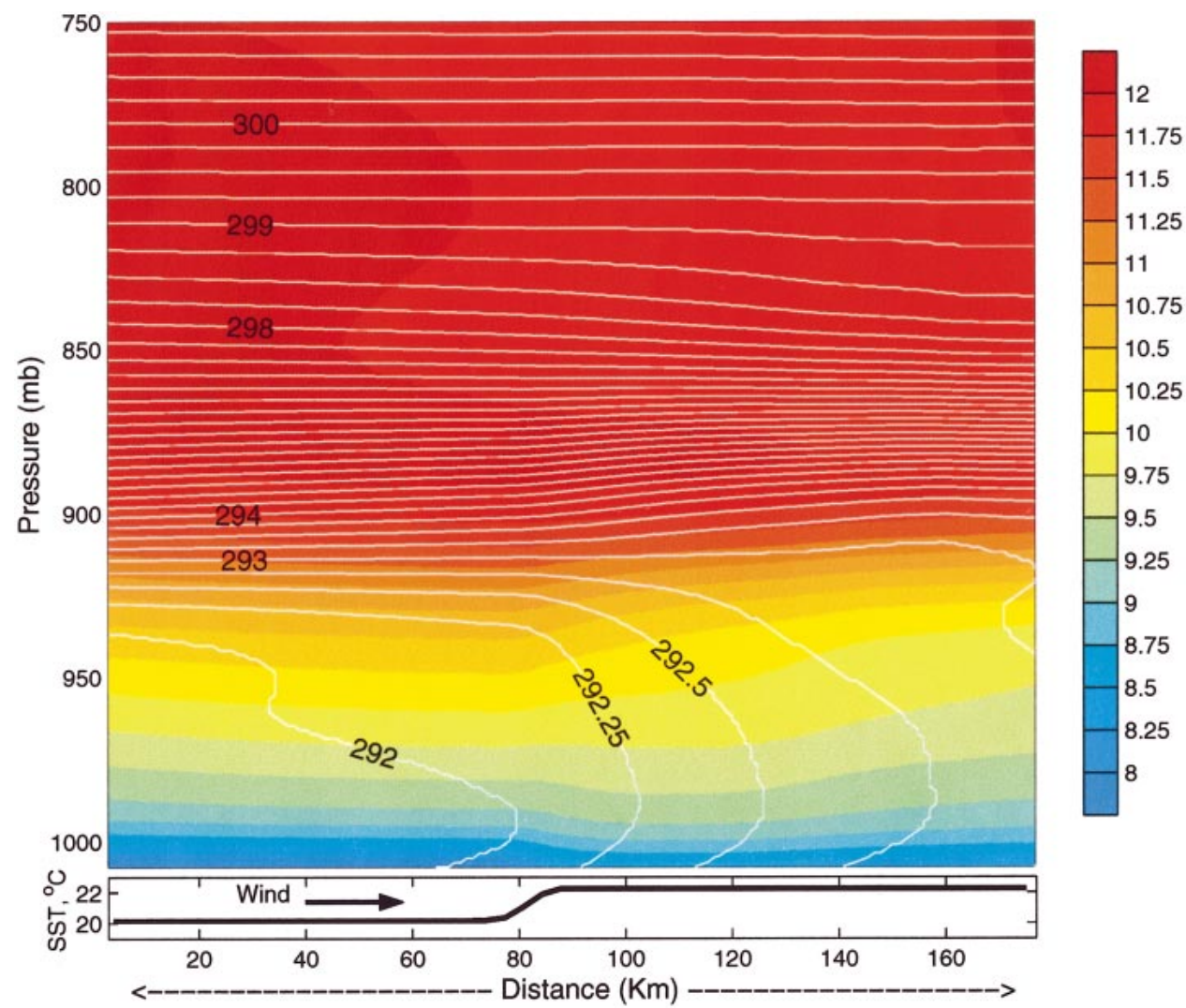

FIG. 7. (top) Potential temperature and wind speed as a function of cross-frontal distance and pressure for the cold-to-warm case at the end of the 15-h simulation (initialized with aircraft data). Contour lines are potential temperature on a contour interval of $0.25 \mathrm{~K}$. Colors represent wind speed with color steps in 0.25 $\mathrm{m} \mathrm{s}^{-1}$. (bottom) SST and wind direction at the surface.

\section{d. Comparison with previous numerical studies}

Modification of the MABL by the underlying SST field has been studied numerically (Wai 1988; Wai and Stage 1989; Koracin and Rogers 1990; Warner et al. 1990; Doyle and Warner 1993). Wai (1988) applied a two-dimensional (2D) MABL model to simulate the evolution of the MABL over a zonally varying SST field. Later, Wai and Stage (1989) used the same model to analyze the dynamical modification effects of an oceanic front on the MABL structure. Their result of the cold-to-warm SST case shows that enhancement of vertical mixing occurs in the MABL when the air mass is advected from the cold to the warm side and the surface wind speed is accelerated. These characteristics are consistent with our simulation. Warner et al. (1990) and Doyle and Warner (1993) performed 3D and 2D numerical modeling experiments to study the impact of the SST resolution on mesoscale coastal processes, and they found that the MABL structure is very sensitive to the SST distribution. Because these numerical experiments studied processes over much larger spatial scales, it is not possible to compare them with our results. Koracin and Rogers (1990) applied a one-dimensional (1D) PBL model to study the response of an idealized MABL to a decrease in SST, in order to simulate an air mass advected from warm to cold water. They found that a stable IBL developed over the cold water, consistent with our numerical results. They then compared the model results of the vertical profile of different variables with the FASINEX observations. Since their model was 1D, they could not study horizontal variability of temperature, wind, wind stress, and sensible heat flux associated with an SST front.

\section{Summary and discussion}

The focus of this study has been on the selection of the PBL parameterizations available in the fifth-generation PSU-NCAR Mesoscale Model (MM5) that best represents MABL processes in the vicinity of an SST front and the evaluation of the performance of MM5 when using the selected PBL parameterization. Of particular interest are simulations of the near-surface wind and wind stress in the vicinity of a sharp SST front. This was done by comparing MM5 simulations with FASINEX observations. Two scenarios were simulated. In both cases the model was initialized with high-level, spatially uniform geostrophic winds giving rise to near- 
surface winds approximately normal to a sharp SST front simulating the front observed during FASINEX. In one case the winds blew from warm to cold water and in the other case from cold to warm. The model requires an initial estimate of the vertical profile in the atmosphere at each grid location. For simplicity, the initial vertical profile was assumed to be uniform over the study domain. For each case simulated, two different initial profiles were used, one obtained from measurements made as part of FASINEX and the other from the NCEP reanalysis. The results are very similar, and only those obtained using the FASINEX observations are summarized here. The effects of the SST front on the MABL are particularly pronounced, as shown by the aircraft observations. For the wind blowing from the warm side of the SST front to the cold side, the wind speed at $30-\mathrm{m}$ height decreases by $20 \%$ over a distance of about $30 \mathrm{~km}$ downstream of the front. The wind stress over the cold side decreases by a factor of 2. The model results, which reproduce these changes quite accurately, show that they are due primarily to the formation of a stable IBL within the mixed layer over the cold water, which restricts the vertical exchange of momentum between the winds aloft and the near-surface winds. For the cold-to-warm case, the synoptic-scale weather system advects relatively cooler air to the front. This gives rise to an unstable MABL with a correspondingly higher coupling between the overlying geostrophic winds and the near-surface winds than observed in the warm-to-cold case and, hence, a much smaller increase in the wind speed and wind stress than the decrease observed in the warm-to-cold case.

The different horizontal adjustment scales of temperature, wind, wind stress, and sensible heat flux associated with a straight SST front indicate that, in addition to oceanic forcing, advection and horizontal convergence and divergence also modify the wind flow field. This cannot be resolved by a 1D model. The fully 3D MM5 with the MRF boundary layer model does, however, appear to capture the appropriate boundary layer physics at the mesoscale (or regional scale) for moderate wind speeds quite well, as indicated by the good agreement in observed and modeled properties for FASINEX presented here.

Acknowledgments. This study was performed with support from the National Aeronautics and Space Administration (Grant NAS5-32965) via Oregon State University as part of the SeaWinds program. Salary support for P. Cornillon was provided by the State of Rhode Island and Providence Plantations. The aircraft data were obtained from the Atmospheric Technology Division (ATD) of the National Center for Atmospheric Research (NCAR). MM5 was also obtained from NCAR.

\section{REFERENCES}

Bright, D., and S. Mullen, 2002: The sensitivity of the numerical simulation of the southwest monsoon boundary layer to the choice of PBL turbulence parameterization in MM5. Wea. Forecasting, 17, 99-114.

Burk, S. D., and W. T. Thompson, 1989: A vertically nested regional numerical weather prediction model with second-order closure physics. Mon. Wea. Rev., 117, 2305-2324.

Chelton, D. B., and Coauthors, 2001: Observations of coupling between surface wind stress and sea surface temperature in the eastern tropical Pacific. J. Climate, 14, 1479-1498.

Cornillon, P., and K.-A. Park, 2001: Warm core ring velocity inferred from NSCAT. Geophys. Res. Lett., 28, 575-578.

Davis, C., T. Warner, E. Astling, and J. Bowers, 1999: Development and application of an operational, relocatable, mesogamma-scale weather analysis and forecasting system. Tellus, 51A, 710-727.

Deardorff, J. W., 1972: Parameterization of the planetary boundary layer for use in general circulation models. Mon. Wea. Rev., 100, 93-106.

Doyle, J., and T. Warner, 1993: The impact of the sea surface temperature resolution on mesoscale coastal processes during GALE IOP2. Mon. Wea. Rev., 121, 313-334.

Dudhia, J., 1993: A nonhydrostatic version of the Penn State-NCAR Mesoscale Model: Validation tests and simulation of an Atlantic cyclone and cold front. Mon. Wea. Rev., 121, 1493-1513.

Friehe, C. A., and Coauthors, 1991: Air-sea fluxes and surface layer turbulence around a sea surface temperature front. J. Geophys. Res., 96, 8593-8609.

Grell, G. A., J. Dudhia, and D. R. Stauffer, 1995: A description of the fifth-generation Penn State/NCAR Mesoscale Model (MM5). NCAR Tech. Note TN-398+STR, 122 pp.

Hong, S., and H. Pan, 1996: Nonlocal boundary layer vertical diffusion in a medium-range forecast model. Mon. Wea. Rev., 124, 2322-2338.

Janjic, Z. I., 1994: The step-mountain Eta coordinate model: Further developments of the convection, viscous sublayer, and turbulence closure schemes. Mon. Wea. Rev., 122, 927-945.

Kelly, K. A., S. Dickinson, M. J. McPhaden, and G. C. Johnson, 2001: Ocean currents evident in satellite wind data. Geophys. Res. Lett., 28, 2469-2472.

Koracin, D., and D. Rogers, 1990: Numerical simulations of the response of the marine atmosphere to ocean forcing. J. Atmos. Sci., 47, 592-611.

Nicholls, S., 1978: Measurements of turbulence by an instrumented aircraft in a convective atmospheric boundary layer over the sea. Quart. J. Roy. Meteor. Soc., 104, 653-676.

Park, K.-A., and P. Cornillon, 2002: Stability-induced modification of sea surface winds over Gulf Stream rings. Geophys. Res. Lett., 29, 2211-2214.

Pleim, J., and A. Xiu, 1995: Development and testing of a surface flux and planetary boundary layer model for application in mesoscale models. J. Appl. Meteor., 34, 16-32.

Shafran, P. C., N. L. Seaman, and G. A. Gayno, 2000: Evaluation of numerical predictions of boundary layer structure during the Lake Michigan Ozone Study. J. Appl. Meteor., 39, 412-426.

Wai, M. M., 1988: Modeling the effects of the spatially varying seasurface temperature on the marine atmospheric boundary layer. J. Appl. Meteor., 27, 5-19.

_ spheric boundary layer structure near the Gulf Stream oceanic front. Quart. J. Roy. Meteor. Soc., 115, 29-44.

Warner, T. T., M. N. Lakhtakia, J. D. Doyle, and R. A. Pearson, 1990: Marine atmospheric boundary layer circulations forced by Gulf Stream sea surface temperature gradients. Mon. Wea. Rev., 118, 309-323.

Wentz, F. J., C. Gentemann, D. Smith, and D. Chelton, 2000: Satellite measurements of sea surface temperature through clouds. Science, 288, 874-850.

Xiu, A., and J. E. Pleim, 2001: Development of a land surface model. Part I: Application in a mesoscale meteorological model. J. Appl. Meteor., 40, 192-209.

Zhang, D., and R. A. Anthes, 1982: A high-resolution model of the planetary boundary layer-Sensitivity tests and comparisons with SESAME-79 data. J. Appl. Meteor., 21, 1594-1609. 